\title{
RESEARCH
}

\section{Serotype Changes and Drug Resistance in Invasive Pneumococcal Diseases in Adults after Vaccinations in Children, Japan, 2010-2013}

\author{
Kimiko Ubukata, Naoko Chiba, Shigeo Hanada, Miyuki Morozumi, Takeaki Wajima, Michi Shouji, \\ Satoshi Iwata; Invasive Pneumococcal Diseases Surveillance Study Group
}

\begin{abstract}
After 7-valent pneumococcal conjugate vaccine (PCV) for children was introduced in Japan in November 2010, we examined changes in Streptococcus pneumoniae serotypes and in genetic antimicrobial drug resistance of isolates from adults with invasive pneumococcal diseases. During April 2010-March 2013, a total of 715 isolates were collected from adults with invasive pneumococcal diseases. Sevenvalent PCV serotypes in adults decreased from $43.3 \%$ to $23.8 \%$, most noticeably for serotype $6 \mathrm{~B}$. Concomitantly, 23-valent pneumococcal polysaccharide vaccine (PPSV23) serotypes decreased from $82.2 \%$ to $72.2 \%$; non-PPSV23 serotypes increased from $13.8 \%$ to $25.1 \%$. Parallel with serotype changes, genotypic penicillin-resistant $S$. pneumoniae decreased from $32.4 \%$ to $21.1 \%$, and 6 non-PPSV23 serotypes emerged (6D, 15A, 15C, 16F, 23A, and 35B). Respective vaccine coverage rates for 13 -valent PCV and PPSV23 differed by disease: $73.9 \%$ and $84.3 \%$ for patients with pneumonia, $56.4 \%$ and $69.2 \%$ for patients with bacteremia and sepsis, and $45.7 \%$ and $69.3 \%$ for patients with meningitis.
\end{abstract}

Ctreptococcus pneumoniae can cause invasive pneumo-

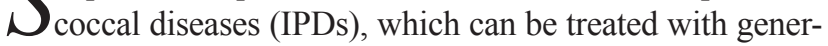
ally effective antimicrobial drugs. In adults, well-known risk factors for IPDs include underlying conditions such as splenectomy, functional asplenia, immunodeficiency, and HIV infection. Risk is also increased with age $>65$ years, diabetes, renal dialysis, and chronic hepatic dysfunction $(1,2)$.

In 2010, the US Advisory Committee on Immunization Practices (ACIP) issued recommendations that all persons $\geq 65$ years of age should be vaccinated with 23 -valent pneumococcal polysaccharide vaccine (PPSV23) to prevent

Author affiliations: Keio University School of Medicine, Tokyo,

Japan (K. Ubukata, N. Chiba, M. Morozumi, S. Iwata); Toranomon Hospital, Tokyo (S. Hanada); Tokyo University of Pharmacy and Life Sciences, Tokyo (T. Wajima); National Cancer Center Hospital, Tokyo (M. Shouji)

DOI: http://dx.doi.org/10.3201/eid2111.142029 pneumococcal diseases (3). In 2012, the ACIP also recommended that 13 -valent pneumococcal conjugate vaccine (PCV13), which the US Food and Drug Administration approved in 2011, be given to adults $\geq 19$ years of age if they have immunocompromising conditions (4). Recently, the ACIP recommended routine administration of both PCV13 and PPSV23 to all adults $\geq 65$ years of age (5).

In the United States, 7-valent pneumococcal conjugate vaccine (PCV7) has been used to vaccinate children since 2000 , resulting in individual and herd immunity and a decline in pneumococcal infection in children (6-9). After PCV7 was introduced, serotype 19A pneumococcal strains with penicillin resistance increased $(8-10)$; the change in 2012 to PCV13 covers serotype 19A (11).

Presently, pneumococcal conjugate vaccines (PCVs) are incorporated into pediatric vaccination schedules in $>120$ countries, and PCV13 has been approved for adults in $>100$ countries. Pneumococcal infections in adults have decreased as an indirect effect of widespread use of PCVs for children $(2,6,8,9,12)$. However, in countries where PCV7 or PCV13 was introduced, overall coverage of serotypes by the vaccine gradually decreased because of pneumococcal serotype replacement from vaccine type to nonvaccine type. In particular, increases of nonvaccine serotypes, such as $6 \mathrm{C}, 15 \mathrm{~A}, 23 \mathrm{~A}$, and $35 \mathrm{~B}$, have been reported in the United States $(13,14)$ and other countries $(15-18)$.

In Japan, PCV7 vaccination was introduced for children $<5$ years of age in November 2010 by the Provisional Fund for the Urgent Promotion of Vaccination. PCV7 was incorporated into routine vaccination schedules in April 2013 and replaced by PCV13 in November 2013. PCV7 rapidly decreased IPD infections in children. However, pneumococcal infections caused by non-PCV7 serotypes (19A, 15A, 15B, 15C and 24) increased in children during $2012(19)$.

Meanwhile, Japan became the first "super-aging" society in the world in 2013 , when $25.1 \%$ of the nation's 
population was $\geq 65$ years of age (Statistics Bureau, Ministry of Internal Affairs and Communications, http:// www.stat.go.jp/english/data/handbook/c0117.htm). Lifestyle-related and other diseases that affect response to infection have increased in older adults, and pneumonia has again become the third leading cause of death in Japan. Nevertheless, the voluntary PPSV23 immunization rate among older persons long remained $<18 \%$. In November 2014, the Japanese Ministry of Health, Labour and Welfare began promoting routine vaccination with PPSV23 for adults $\geq 65$ years of age.

Because of these developments, we sought to clarify changes in serotypes and in genetic antimicrobial resistance in isolates from adults with IPDs after PCV7 for children was introduced in Japan. We describe capsular serotypes, drug-resistance genotypes, and multilocus sequence typing in isolates from adults with IPDs, and we examine the relationships of these factors to specific IPDs.

\section{Methods}

\section{Patients and Pneumococcal Strains}

Our study included adult patients $(\geq 19$ years of age) with IPD. Pneumococcal isolates from sterile clinical samples such as blood, cerebrospinal fluid, pleural effusion, and joint fluid were collected from clinical laboratories at 341 hospitals participating in this IPD surveillance study. Each hospital had a microbiology laboratory, and the hospitals were distributed nearly uniformly throughout Japan. The hospitals participated in the surveillance project after written permission was obtained from laboratory or hospital directors.

From April 2010 through March 2013, a total of 715 pneumococcal isolates were collected for the study: 275 during April 2010-March 2011, the first surveillance period; 213 during April 2011-March 2012, the second period; and 227 during April 2012-March 2013, the third period. This large-scale IPD surveillance for adults was performed in conjunction with IPD surveillance for children (19). During the first surveillance period, the rate of voluntary PCV7 vaccination for children was $\approx 10 \%$. The second period occurred simultaneously with the Urgent Promotion of Vaccination incentive for children, and the immunization rate was $\approx 50 \%-60 \%$. The third period occurred just before the transition from PCV7 to PCV13 for children, and the PCV7 immunization rate was $\approx 80 \%-$ $90 \%$. However, the rate of voluntary vaccination with PPSV2 3 in adults remained $<18 \%$ throughout the surveillance periods.

The collected pneumococcal isolates were sent promptly from each clinical laboratory to our laboratory (Molecular Epidemiology for Infectious Agents, Kitasato Institute for Life Sciences, Kitasato University, Tokyo, Japan), accompanied by survey forms completed by attending physicians but not identifying patients in compliance with ethical guidelines for epidemiology in Japan. The surveys collected information on patient's age at illness onset, sex, clinical manifestations, blood test results at hospitalization, and outcome. Clinical manifestations and diagnoses were verified in all patients, according to diagnostic criteria and guidelines for sepsis and related conditions (20).

\section{Serotypes and Antimicrobial Drug-Resistant Genotypes}

Serotypes were determined by the capsular quellung reaction by using antiserum purchased from the Statens Serum Institute (Copenhagen, Denmark). By using real-time PCR methods described previously (21), alterations were identified in 3 penicillin-binding protein (PBP) genes mediating $\beta$-lactam resistance in $S$. pneumoniae: pbpla (encoding enzyme PBP1A), $p b p 2 x$ (encoding PBP2X), and $p b p 2 b$ (encoding PBP2B). Amino acid substitutions within or near each PBP's conserved amino acid motifs, such as serinethreonine (Thr)-methionine-lysine (STMK), were detected by using real-time PCR. The mef (A) and erm (B) genes mediating macrolide resistance were also identified by real-time PCR (21). Quinolone resistance was analyzed by sequencing the quinolone-resistance-determining region in the genes $g y r A, \operatorname{gyr} B, \operatorname{par} C$, and $\operatorname{parE}$ in strains with MICs of levofloxacin of $>4 \mu \mathrm{g} / \mathrm{mL}$ (22).

Gene analysis identified genotypes ( $\mathrm{g}$ ) on the basis of their responses to $\beta$-lactam antimicrobial drugs: penicillinsusceptible $S$. pneumoniae (gPSSP) possessing 3 normal $p b p$ genes; penicillin-intermediate $S$. pneumoniae (gPISP), also classified as gPISP ( $p b p 2 x)$, gPISP $(p b p 2 b)$, gPISP $(p b p 1 a+p b p 2 x)$, or gPISP $(p b p 2 x+p b p 2 b)$; and penicillinresistant $S$. pneumoniae (gPRSP), which possessed all 3 abnormal pbp genes $(19,21)$. Macrolide-resistant genotypes were also represented variously: macrolide-susceptible $S$. pneumoniae that possessed no resistance genes; macrolide resistance mediated by the mef(A) gene, MLR-mef(A); macrolide resistance mediated by the erm(B) gene, MLR$\operatorname{erm}(\mathrm{B})$; and macrolide resistance involving both genes, MLR-mef(A)+erm(B).

Identification of capsular type by the quellung reaction and resistance genotyping by real-time PCR was performed within 1 day of sample collection for each strain. Results were reported immediately to the medical staff at the referring hospital.

\section{Antimicrobial Susceptibility Testing}

MICs of 7 intravenous antimicrobial agents (penicillin, ampicillin, cefotaxime, ceftriaxone, meropenem, panipenem, and vancomycin) were determined for all pneumococcal isolates by agar-dilution methods (23). We obtained each agent from the respective manufacturer. 


\section{Multilocus Sequence Typing}

Multilocus sequence typing (MLST; http://www.MLST. net) was performed for nonvaccine serotype strains, except for PPSV23 serotypes, according to previously described methods with minor modifications (24). Primers used were based on sequences listed by the US Centers for Disease Control and Prevention (http://www.cdc.gov/ncidod/ biotech/strep/alt-MLST-primers.htm). Analyses by using MLST and eBURST (Department of Infectious Disease Epidemiology, Imperial College of London, UK) were performed, as described by the MLST website (http://spneumoniae.mlst.net).

\section{Statistical Analysis}

We assessed differences in serotypes by age groups, clinical symptoms and signs, resistance types, and surveillance periods. To determine whether differences were statistically significant, we performed $\chi^{2}$ tests or the Fisher exact test by using Ekuseru-Toukei 2012 software for statistics (Social Survey Research Information, Tokyo, Japan).

\section{Results}

\section{Yearly Changes in Pneumococcal Serotypes}

During each annual surveillance period (April-March) during 2010-2013, pneumococcal serotypes from IPD isolates varied (Table 1). All strains were isolated from sterile samples, such as blood, cerebrospinal fluid, pleural effusion, or joint fluid.

During all surveillance periods, the estimated voluntary inoculation rate for PPSV23 in adults was $\leq 18 \%$ in Japan. In February 2010, the vaccination incentive for PCV7 in children began on a voluntary basis. In November 2010, the Special Fund for the Urgent Promotion of Vaccination was initiated, and PCV7 vaccination of children $<5$ years of age became an official priority throughout

\begin{tabular}{|c|c|c|c|c|}
\hline Vaccine serotype & $\begin{array}{c}\text { 2010-2011, no. (\%), } \\
n=275\end{array}$ & $\begin{array}{c}\text { 2011-2012, no. (\%), } \\
n=213\end{array}$ & $\begin{array}{c}2012-2013, \text { no. }(\%) \\
n=227\end{array}$ & $p$ value \\
\hline \multicolumn{5}{|l|}{ PCV7 } \\
\hline 4 & $14(5.1)$ & $17(8.0)$ & $7(3.1)$ & 0.075 \\
\hline $6 \mathrm{~B}$ & $41(14.9)$ & $24(11.3)$ & $12(5.3)$ & 0.003 \\
\hline $9 \mathrm{~V}$ & $7(2.5)$ & $5(2.3)$ & $1(0.4)$ & 0.168 \\
\hline 14 & $21(7.6)$ & $16(7.5)$ & $17(7.5)$ & 0.998 \\
\hline $18 \mathrm{C}$ & $1(0.4)$ & $1(0.5)$ & $1(0.4)$ & ND \\
\hline $19 \mathrm{~F}$ & $14(5.1)$ & $8(3.8)$ & $7(3.1)$ & 0.511 \\
\hline $23 \mathrm{~F}$ & $21(7.6)$ & $13(6.1)$ & $9(4.0)$ & 0.232 \\
\hline Total & 119 (43.3) & $84(39.4)$ & $54(23.8)$ & $<0.001$ \\
\hline \multicolumn{5}{|l|}{ PCV13 } \\
\hline 1 & $1(0.4)$ & $1(0.5)$ & 0 & ND \\
\hline 3 & $45(16.4)$ & 27 (12.7) & $42(18.5)$ & 0.226 \\
\hline 5 & 0 & 0 & $1(0.4)$ & ND \\
\hline $6 \mathrm{~A}$ & $11(4.0)$ & $4(1.9)$ & $6(2.6)$ & 0.367 \\
\hline $7 \mathrm{~F}$ & $9(3.3)$ & $2(0.9)$ & $3(1.3)$ & 0.128 \\
\hline $19 \mathrm{~A}$ & $18(6.5)$ & $11(5.2)$ & $17(7.5)$ & 0.593 \\
\hline Total & $203(73.8)$ & $129(60.6)$ & $123(54.2)$ & $<0.001$ \\
\hline \multicolumn{5}{|l|}{ PPSV23 } \\
\hline $10 \mathrm{~A}$ & $10(3.6)$ & $8(3.8)$ & $11(4.8)$ & 0.754 \\
\hline $11 \mathrm{~A}$ & $3(1.1)$ & $8(3.8)$ & $5(2.2)$ & 0.142 \\
\hline 15B & $3(1.1)$ & $4(1.9)$ & $5(2.2)$ & 0.605 \\
\hline $22 \mathrm{~F}$ & $10(3.6)$ & 19 (8.9) & 18 (7.9) & 0.040 \\
\hline Otherł & $8(2.9)$ & $1(0.5)$ & 8 (3.5) & 0.082 \\
\hline Total & $226(82.2)$ & $165(77.5)$ & $164(72.2)$ & 0.036 \\
\hline \multicolumn{5}{|c|}{ Nonvaccine serotype } \\
\hline $6 \mathrm{C}$ & $13(4.7)$ & $12(5.6)$ & $17(7.5)$ & 0.407 \\
\hline $15 \mathrm{~A}$ & $6(2.2)$ & $10(4.7)$ & $8(3.5)$ & 0.310 \\
\hline $15 \mathrm{C}$ & 0 & $4(1.9)$ & $4(1.8)$ & ND \\
\hline $23 \mathrm{~A}$ & $2(0.7)$ & $8(3.8)$ & $8(3.5)$ & 0.053 \\
\hline $35 B$ & $7(2.5)$ & $6(2.8)$ & $9(4.0)$ & 0.626 \\
\hline 37 & $3(1.1)$ & 0 & $1(0.4)$ & ND \\
\hline 38 & $3(1.1)$ & $2(0.9)$ & $3(1.3)$ & 0.928 \\
\hline Other§ & $3(1.1)$ & $2(0.9)$ & $5(2.2)$ & 0.454 \\
\hline Total & 37 (13.5) & $44(20.7)$ & $55(24.2)$ & 0.007 \\
\hline
\end{tabular}

$\begin{array}{lcl}\text { Nontypeable } & 1(0.4) & 0 \\ { }^{*} \text { Years run from April } 1 \text { to March } 31 \text { of the following year. ND, not determined because of a low number of strains. }\end{array}$

tp values characterize comparisons of 2010-2011, 2011-2012, and 2012-2013.

¥Serotypes $12 \mathrm{~F}, 20$, and $33 \mathrm{~F}$.

§Serotypes 6D, 7C, 16F, 18B, 24F, and 34

IThese serotypes were excluded from the statistical analysis because they were unclassifiable. 
Japan. Estimates of the PCV7 immunization rate in children was $<10 \%$ in $2010,50 \%-60 \%$ in 2011 , and $80 \%-$ $90 \%$ in 2012 (19).

PPSV23 coverage of serotypes found in IPD isolates decreased significantly each year, from $82.2 \%$ in 2010 to $77.5 \%$ in 2011 to $72.2 \%$ in 2012 ( $\mathrm{p}=0.036$ ). Respective coverages with PCV7 and PCV13 also decreased significantly, from $43.3 \%$ and $73.8 \%$ in 2010 to $39.4 \%$ and $60.6 \%$ in 2011 to $23.8 \%$ and $54.2 \%$ in 2012 , respectively $(\mathrm{p}<0.001)$. Although serotype $22 \mathrm{~F}$ increased significantly in IPD isolates, yearly decreases of serotype $6 \mathrm{~B}$ contributed markedly to decreases in PPSV23 coverage. Nonvaccine serotypes (i.e., non-PPSV23) increased significantly during the surveillance periods from $13.5 \%$ in 2010 to $20.7 \%$ in 2011 to $24.2 \%$ in 2012 ( $\mathrm{p}=0.007)$.

Introduction of PCV7 in children indirectly affected adults with IPD, shown by changes in each serotype during 2010-2012 (online Technical Appendix Figure 1, http:// wwwnc.cdc.gov/EID/article/21/11/14-2029-Techapp.pdf). Decreases occurred in PCV7 serotypes and serotype 6A, the latter of which exhibits cross-immunity with $6 \mathrm{~B}$, but almost all other serotypes except those in PCV13 increased, especially serotypes $22 \mathrm{~F}, 6 \mathrm{C}, 23 \mathrm{~A}, 15 \mathrm{C}, 15 \mathrm{~A}$, and $35 \mathrm{~B}$.

\section{Yearly Changes in Genotypes Resistant to Penicillin, Macrolides, and Quinolones}

Genotypes resistant to penicillin, macrolides, and quinolones varied during the surveillance periods (Table 2 ). Among genotypes resistant to penicillin, $40 \%$ were gPISP $(p b p 2 x), 26 \%$ were gPRSP, $10.2 \%$ were gPISP $(p b p 1 a+p b p 2 x)$, and $5.9 \%$ were gPISP $(p b p 2 x+p b p 2 b)$. Only $16.1 \%$ were gPSSP strains without any abnormal $p b p$ genes. Other genotypes were gPISP ( $p b p 2 b ; 1.3 \%)$ and gPISP $($ pbpla $12 b ; 0.6 \%)$. In contrast to a gradual increase in gPISP $(p b p 2 x+p b p 2 b ; \mathrm{p}=0.025)$, gPRSP decreased significantly over the surveillance periods $(\mathrm{p}=$ 0.008 ). In addition, $89.7 \%$ of all pneumococcal strains possessed mef(A) or erm(B) genes that mediated macrolide resistance: $23.6 \%$ carried the mef(A) gene mediating intermediate macrolide resistance; $56.9 \%$ carried the $\operatorname{erm}(\mathrm{B})$ gene mediating high macrolide resistance; and $9.1 \%$ possessed both genes. Macrolide-susceptible strains accounted for only $10.3 \%$. Furthermore, only $0.7 \%$ of strains were highly resistant to levofloxacin ( $\mathrm{MIC}>16 \mu \mathrm{g} / \mathrm{mL}$ ) and possessed mutations in both gyr $\mathrm{A}$ and $\operatorname{parC}$ genes. Intermediate-resistance strains (MIC 4 $\mu \mathrm{g} / \mathrm{mL}$ ) that possessed the $\operatorname{parC}$ mutation accounted for $1.3 \%$ of strains.

\section{Yearly Changes in Resistance Genotypes and Serotypes}

Yearly changes in genotypes and serotypes affecting $\beta$-lactam resistance also occurred during the 3 periods (Figure). Decreases closely related to a reduction of serotypes $6 \mathrm{~B}, 19 \mathrm{~F}$, and $23 \mathrm{~F}$, but not of serotype 14 , were found for a number of gPRSP. Emergence of gPRSP was evident among 6 non-PPSV23 serotypes (6D, 15A, 15C, 16F, 23A, and $35 \mathrm{~B}$ ), although such resistance strains were few. Almost all non-PPSV23 serotype strains showed macrolide resistance (online Technical Appendix Figure 2), which did not change significantly from year to year (Table 2).

\section{Invasive Pneumococcal Diseases and Patient Age}

To examine relationships between IPDs and patient age at illness onset, we classified IPDs into 4 categories (Table $3)$ : pneumonia $(\mathrm{n}=375)$, including cases of empyema ( $\mathrm{n}$ $=17)$ and pleuritis $(\mathrm{n}=16)$; bacteremia and sepsis with no obvious focus $(\mathrm{n}=172)$, including sepsis $(\mathrm{n}=51)$, severe

\begin{tabular}{|c|c|c|c|c|c|}
\hline Genotype & $\begin{array}{c}\text { Total, no. }(\%), \\
\mathrm{N}=715\end{array}$ & $\begin{array}{c}\text { 2010-2011, no. (\%), } \\
n=275\end{array}$ & $\begin{array}{c}2011-2012, \text { no. }(\%), \\
n=213\end{array}$ & $\begin{array}{c}\text { 2012-2013, no. (\%), } \\
n=227\end{array}$ & $\mathrm{p}$ value \\
\hline \multicolumn{6}{|l|}{ Penicillin resistance } \\
\hline gPSSP & $115(16.1)$ & $42(15.3)$ & $40(18.8)$ & $33(14.5)$ & 0.431 \\
\hline gPISP $(p b p 2 x)$ & $286(40.0)$ & $96(34.9)$ & $89(41.8)$ & $101(44.5)$ & 0.076 \\
\hline gPISP $(p b p 2 b)$ & $9(1.3)$ & $5(1.8)$ & 0 & $4(1.8)$ & ND \\
\hline gPISP $(p b p 1 a+2 x)$ & $73(10.2)$ & 30 (10.9) & $23(10.8)$ & $20(8.8)$ & 0.701 \\
\hline gPISP $(p b p 1 a+2 b)$ & $4(0.6)$ & $3(1.1)$ & $1(0.5)$ & 0 & ND \\
\hline gPISP $(p b p 2 x+2 b)$ & $42(5.9)$ & $10(3.6)$ & $11(5.2)$ & $21(9.3)$ & 0.025 \\
\hline $\operatorname{gPRSP}(p b p 1 a+2 x+2 b)$ & $186(26.0)$ & $89(32.4)$ & $49(23.0)$ & $48(21.1)$ & 0.008 \\
\hline \multicolumn{6}{|l|}{ Macrolide resistance } \\
\hline Resistance gene (-) & $74(10.3)$ & $34(12.4)$ & $16(7.5)$ & $24(10.6)$ & 0.216 \\
\hline $\operatorname{mef}(\mathrm{A})$ gene & $169(23.6)$ & $63(22.9)$ & $56(26.3)$ & $50(22.0)$ & 0.538 \\
\hline erm(B) gene & 407 (56.9) & $152(55.3)$ & $123(57.7)$ & $132(58.1)$ & 0.777 \\
\hline$m e f(\mathrm{~A})$ and $\operatorname{erm}(\mathrm{B})$ & $65(9.1)$ & $26(9.5)$ & $18(8.5)$ & $21(9.3)$ & 0.925 \\
\hline \multicolumn{6}{|l|}{ Quinolone resistance } \\
\hline gyrA+parC & $5(0.7)$ & $2(0.7)$ & $3(1.4)$ & 0 & ND \\
\hline parc & 9 (1.3) & $5(1.8)$ & $1(0.5)$ & $3(1.3)$ & ND \\
\hline
\end{tabular}




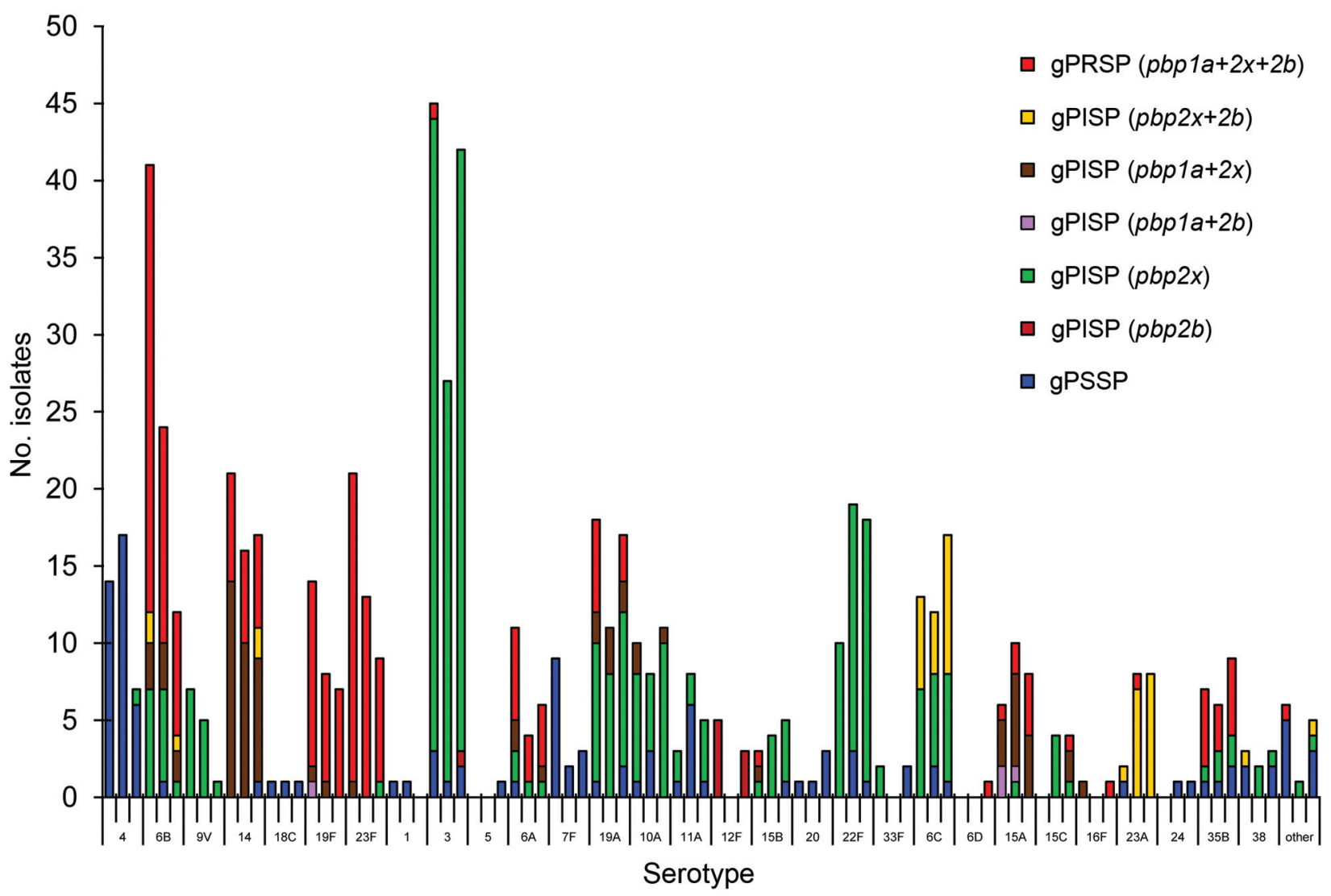

Figure. Yearly changes in number of serotypes and in penicillin resistance in genotypes found in isolates from adults with invasive pneumococcal diseases, Japan, April 2010-March 2013. Serotypes are shown for each of the 3 yearly surveillance periods: April 2010-March 2011, April 2011-March 2012, and April 2012-March 2013. Short tic marks on horizontal axis represent yearly number of isolates for specific serotypes; longer tic marks represent the 3-year surveillance period for each serotype. gPSSP, genotypic penicillinsusceptible Streptococcus pneumoniae; gPISP, genotypic penicillin-intermediate resistant S. pneumoniae; gPRSP, genotypic penicillinresistant $S$. pneumoniae. Parentheses enclose abnormal pbp genes that mediate penicillin resistance.

sepsis $(\mathrm{n}=57)$, and septic shock $(\mathrm{n}=24)$; meningitis $(\mathrm{n}$ $=127)$; and others $(\mathrm{n}=41)$, including cellulitis $(\mathrm{n}=7)$, arthritis $(n=6)$, spondylitis $(n=4)$, and peritonitis $(n=$ $3)$. Pneumonia (52.4\%) was the most common category of IPDs, followed by bacteremia and sepsis $(24.1 \%)$ and meningitis $(17.8 \%)$. Mean age of patients with meningitis was 65 years, younger than those with pneumonia or bacteremia and sepsis (mean age 74 and 70 years, respectively). Meningitis occurred significantly more often among patients $\leq 64$ years of age, in contrast to pneumonia, which occurred most often in persons $\geq 75$ years of age $(p<0.001)$.

Data for deaths and survival were available for 656 $(91.7 \%)$ of the 715 patients. Proportions of deaths occurring within 30 days of hospitalization increased significantly with age: $6.0 \%$ at $19-49$ years, $17.8 \%$ at $50-64$ years, $17.9 \%$ at $65-74$ years, $25.4 \%$ at $75-84$ years, and $26.3 \%$ at $\geq 85$ years $(\mathrm{p}=0.002)$. Overall rate of death occurring within 30 days after hospitalization was $21.3 \%$; overall rate for serious sequelae was $10 \%$.

\section{Serotype Distribution by Disease}

A comparison of proportions of serotypes included in PCV7, PCV13, PPSV23, and non-PPSV23 by disease category (i.e., pneumonia, bacteremia and sepsis, meningitis, and others) showed that frequency of serotypes differed considerably by type of IPD (Table 4). Prevalence of serotypes 3,14, and 19A was higher in isolates of patients with pneumonia than in those from patients with other illnesses ( $p$ value range $<0.001-0.076$ ). In contrast, serotypes $10 \mathrm{~A}, 15 \mathrm{~A}, 23 \mathrm{~A}$, and $23 \mathrm{~F}$ were significantly more prevalent in isolates of patients with meningitis than in those from patients with other illnesses ( $\mathrm{p}$ value range $<0.001-0.004$ ).

Coverages for vaccines among all isolates collected and examined during the study duration were $35.5 \%$ for PCV7, $63.6 \%$ for PCV13, and $77.6 \%$ for PPSV23. Respective coverages of PCV13 and PPSV23 differed significantly for each IPD group: $73.9 \%$ and $84.3 \%$ for pneumonia, $56.4 \%$ and $69.2 \%$ for bacteremia and sepsis, $45.7 \%$ and $69.3 \%$ for meningitis, and $56.1 \%$ and $78.0 \%$ for others $(\mathrm{p}<0.001$ for 
Invasive Pneumococcal Diseases, Japan

Table 3. Isolates positive for invasive pneumococcal diseases in adults, by age group, Japan, April 2010-March 2013

\begin{tabular}{|c|c|c|c|c|c|c|c|c|}
\hline \multirow[b]{2}{*}{ Disease } & \multicolumn{6}{|c|}{ No. (\%) } & \multirow{2}{*}{$\begin{array}{c}\text { Mean age, y } \\
( \pm S D)\end{array}$} & \multirow[b]{2}{*}{$\mathrm{p}$ value } \\
\hline & Total & 19-49 & $50-64$ & $65-74$ & $75-84$ & $\geq 85$ & & \\
\hline Pneumonia* $^{*}$ & $375(52.4)$ & $33(39.8)$ & $66(42.0)$ & $103(49.8)$ & $105(60.7)$ & $68(71.6)$ & $74(14.9)$ & $<0.001$ \\
\hline Bacteremia and sepsis $†$ & $172(24.1)$ & $20(24.1)$ & $42(26.8)$ & $55(26.6)$ & $34(19.7)$ & $21(22.1)$ & $70(15.0)$ & 0.497 \\
\hline Meningitis & $127(17.8)$ & $24(28.9)$ & 38 (24.2) & 37 (17.9) & $22(12.7)$ & $6(6.3)$ & $65(14.4)$ & $<0.001$ \\
\hline Otherf & $41(5.7)$ & $6(7.2)$ & $11(7.0)$ & $12(5.8)$ & $12(6.9)$ & 0 & $67(14.5)$ & 0.133 \\
\hline Total & 715 & 83 & 157 & 207 & 173 & 95 & $70(14.9)$ & \\
\hline
\end{tabular}

all). The most prevalent serotype was serotype 3 (15.9\%), followed by serotypes $6 \mathrm{~B}(10.8 \%), 14(7.6 \%), 22 \mathrm{~F}(6.6 \%)$, 19A (6.4\%), and 23F (6.0\%). Death rates did not differ significantly by pneumococcal serotype.

\section{Antimicrobial Drug Susceptibility by Genotype}

The online Technical Appendix Table shows susceptibilities (50\% MIC, $90 \% \mathrm{MIC}$, and MIC range) of 6 parenteral $\beta$-lactam agents for $S$. pneumoniae strains $(\mathrm{n}=710)$. PBP gene alterations affect MICs of penicillin, ampicillin, cefotaxime, and meropenem (online Technical Appendix Figure 3). Most strains in this study were gPISP with $p b p 2 x$ gene alterations that reduced susceptibility to cephalosporin agents rather than to penicillin. MICs of cefotaxime and ceftriaxone were affected more by $p b p 2 x$ alterations than by $p b p 2 b$ alterations. In contrast, MICs of penicillin, ampicillin, and meropenem were affected more by $p b p 2 b$ alterations than by $p b p 2 x$ alterations. Strains showing MICs $\geq 4 \mu \mathrm{g} / \mathrm{mL}$ to cefotaxime had $p b p 2 a$ gene alteration and also had pbp $1 a, p b p 2 x$, and $p b p 2 b$ gene alterations (data not shown).

\section{MLST in Non-PCV13 Serotype Strains}

MLST results for 92 strains (non-PCV13 serotypes) collected during 2012 and results for 2 gPRSPs (serotypes 15B collected during 2010 and 23A collected during 2011) indicate that sequence types (STs), 8 of which were new, and clonal complexes (CCs) varied (Table 5). We identified 3 new STs of gPRSPs possessing macrolideresistant genes: ST6138 (CC81) in serotype 15C, ST8351 (CC3117) in serotype 16F, and ST9619 (CC156) in serotype 23A. Also, we identified gPRSPs of ST282 (CC81) in serotype 6D, reported from South Korea in 2008 and derived from Vietnam serotype 23F in 1996; ST63 (CC63) in serotype 15A, derived from Sweden ${ }^{15 \mathrm{~A}}-25$ in 1992; ST83 (CC81) in serotype 15B, reported from South Korea in 2007 and derived from Taiwan serotype 23F in 1997; and ST558 (CC558) in serotype 35B, reported from the United States in 1999 (Table 5). We confirmed that all gPRSPs examined in our study had abnormal PBPs by DNA sequencing: substitutions of Thr371Serine or Thr371Alanine (Ala) within conserved amino acid motif STMK in PBP1A; Thr338Ala within STMK in PBP2X; and Thr445Ala adjacent to the serine-serine-asparagine amino acid motif in PBP2B, respectively.

\section{Discussion}

Wide use of PCV7 or PCV13 in young children has contributed to a decline in IPD (6-9) and other pneumococcal diseases, including pneumonia $(25,26)$ and otitis media $(27,28)$. The decline resulted from both direct vaccine effect and herd immunity.

In the United States, introduction of PCV7 led to decreased rates of IPD, resulting from vaccine-related strains in children and in unvaccinated adults because of indirect effects of pediatric use $(6,29,30)$. After increased incidence of serotype 19A among causative pathogens in children, multivalent PCV13 replaced PCV7 in 2010 (11). PCV13 now has been introduced in $>120$ countries, and various pneumococcal diseases have decreased as a result. Unfortunately, serotype replacement by non-PCV13 serotypes such as $6 \mathrm{C}, 15 \mathrm{~B}, 22 \mathrm{~F}, 23 \mathrm{~A}$, and $35 \mathrm{~B}$ has also ensued $(13,14,16-18,31)$.

In Japan, incorporation of PCV7 and Haemophilus influenzae type $\mathrm{b}$ conjugate vaccine into routine vaccination schedules for children occurred later than in other countries and was spurred by the Provisional Special Fund for the Urgent Promotion of Vaccination, initiated in November 2010. The vaccination rate for children improved rapidly from $<10 \%$ in 2010 to $50 \%-60 \%$ in 2011 and $80 \%-90 \%$ in 2012. Routine PCV7 for children was implemented officially in April 2013 and was replaced with PCV13 in November 2013.

Although PPSV23 was approved in 1988, few $(<18 \%$ in 2012) adults voluntarily received PPSV23 vaccination. Since October 2014, vaccination with PPSV23 in adults $\geq 65$ years of age has been supported by public government funding. However, at this time, vaccination rates are unclear because these older persons can receive 1 PPSV23 vaccination over a 5 -year period.

In our large-scale surveillance, we aimed to clarify molecular epidemiology for pneumococci and $\beta$-hemolytic streptococci and to collect background data on patients with IPD throughout Japan during April 2010-March 2013. Pediatric IPD caused by PCV7 serotypes and other PCV7related 6A serotypes decreased significantly soon after 
Table 4. Pneumococcal serotypes by type of invasive pneumococcal diseases in adults, Japan, April 2010-March 2013*

\begin{tabular}{|c|c|c|c|c|c|c|}
\hline Serotype & $\begin{array}{c}\text { Pneumonia, } \\
\text { no. }(\%), \mathrm{n}=375\end{array}$ & $\begin{array}{c}\text { Bacteremia and sepsis, } \\
\text { no. }(\%), n=172\end{array}$ & $\begin{array}{c}\text { Meningitis, } \\
\text { no. }(\%), n=127\end{array}$ & $\begin{array}{c}\text { Others, no. (\%), } \\
\mathrm{n}=41\end{array}$ & $\begin{array}{l}\text { Total, no. (\%), } \\
\mathrm{N}=715\end{array}$ & $\mathrm{p}$ value $†$ \\
\hline \multicolumn{7}{|l|}{ PCV7 serotypes } \\
\hline 4 & $25(6.7)$ & $8(4.7)$ & $5(3.9)$ & 0 & $38(5.3)$ & 0.403 \\
\hline $6 \mathrm{~B}$ & $42(11.2)$ & $20(11.6)$ & $11(8.7)$ & $4(9.8)$ & $77(10.8)$ & 0.667 \\
\hline $9 \mathrm{~V}$ & $10(2.7)$ & $3(1.7)$ & 0 & 0 & $13(1.8)$ & 0.161 \\
\hline 14 & $36(9.6)$ & $9(5.2)$ & $6(4.7)$ & $3(7.3)$ & $54(7.6)$ & 0.076 \\
\hline $18 \mathrm{C}$ & $1(0.3)$ & $1(0.6)$ & $1(0.8)$ & 0 & $3(0.4)$ & ND \\
\hline $19 \mathrm{~F}$ & $14(3.7)$ & $9(5.2)$ & $4(3.1)$ & $2(4.9)$ & $29(4.1)$ & 0.617 \\
\hline $23 \mathrm{~F}$ & $16(4.3)$ & $7(4.1)$ & $15(11.8)$ & 5 (12.2) & $43(6.0)$ & 0.004 \\
\hline Total & $144(38.4)$ & $57(32.6)$ & $42(32.3)$ & $14(34.1)$ & $257(35.5)$ & 0.325 \\
\hline \multicolumn{7}{|c|}{ Additional PCV13 serotypes } \\
\hline 3 & $84(22.4)$ & $17(9.9)$ & $7(5.5)$ & $6(14.6)$ & $114(15.9)$ & $<0.001$ \\
\hline $6 \mathrm{~A}$ & $7(1.9)$ & $9(5.2)$ & $4(3.1)$ & $1(2.4)$ & $21(2.9)$ & 0.101 \\
\hline $7 F$ & $10(2.7)$ & $2(1.2)$ & $2(1.6)$ & 0 & $14(2.0)$ & 0.463 \\
\hline $19 \mathrm{~A}$ & $32(8.5)$ & $9(5.2)$ & $3(2.4)$ & $2(4.9)$ & $46(6.4)$ & 0.035 \\
\hline Other $\ddagger$ & 0 & $3(1.7)$ & 0 & 0 & $3(0.4)$ & ND \\
\hline Total & 277 (73.9) & $97(56.4)$ & $58(45.7)$ & $23(56.1)$ & 455 (63.6) & $<0.001$ \\
\hline \multicolumn{7}{|c|}{ Additional PPSV23 serotypes } \\
\hline $10 \mathrm{~A}$ & $6(1.6)$ & $8(4.7)$ & $11(8.7)$ & $4(9.8)$ & $29(4.1)$ & 0.001 \\
\hline $11 \mathrm{~A}$ & $10(2.7)$ & $3(1.7)$ & $3(2.4)$ & 0 & $16(2.2)$ & 0.798 \\
\hline 15B & $4(1.1)$ & $4(2.3)$ & $2(1.6)$ & $2(4.9)$ & $12(1.7)$ & 0.533 \\
\hline $22 \mathrm{~F}$ & $20(5.3)$ & $12(7.0)$ & $12(9.4)$ & $3(7.3)$ & $47(6.6)$ & 0.269 \\
\hline Other§ & $6(1.6)$ & $4(2.3)$ & $6(4.7)$ & $1(2.4)$ & $17(2.4)$ & 0.139 \\
\hline Totalף & $316(84.3)$ & $119(69.2)$ & $88(69.3)$ & $32(78.0)$ & $555(77.6)$ & $<0.001$ \\
\hline \multicolumn{7}{|c|}{ Nonvaccine serotypes } \\
\hline $6 \mathrm{C}$ & $21(5.6)$ & $10(5.8)$ & $7(5.5)$ & $4(9.8)$ & $42(5.9)$ & 0.994 \\
\hline $15 \mathrm{~A}$ & $5(1.3)$ & $9(5.2)$ & $9(7.1)$ & $1(2.4)$ & $24(3.4)$ & 0.003 \\
\hline $15 \mathrm{C}$ & $1(0.3)$ & $4(2.3)$ & $3(2.4)$ & 0 & $8(1.1)$ & ND \\
\hline $23 \mathrm{~A}$ & $2(0.5)$ & $7(4.1)$ & $8(6.3)$ & $1(2.4)$ & $18(2.5)$ & $<0.001$ \\
\hline $35 \mathrm{~B}$ & $7(1.9)$ & $9(5.2)$ & $4(3.1)$ & $2(4.9)$ & $22(3.1)$ & 0.101 \\
\hline 38 & $6(1.6)$ & $1(0.6)$ & $1(0.8)$ & 0 & $8(1.1)$ & ND \\
\hline Other\# & $7(1.9)$ & $4(2.3)$ & $3(2.4)$ & 0 & $14(2.0)$ & 0.918 \\
\hline Total & $49(13.1)$ & $44(25.6)$ & $35(27.6)$ & $8(19.5)$ & $136(19.0)$ & $<0.001$ \\
\hline Nontypeable $^{\star \star}$ & $3(0.8)$ & 0 & 0 & 0 & $3(0.4)$ & \\
\hline \multicolumn{7}{|c|}{$\begin{array}{l}\text { *ND, not determined because of low number of strains. PCV7, 7-valent pneumococcal conjugate vaccine; PCV13, 13-valent pneumococcal conjugate } \\
\text { vaccine; PPSV23, 23-valent pneumococcal polysaccharide vaccine. } \\
\text { †Significant difference obtained by comparing pneumonia, sepsis, and meningitis. } \\
\text { †Serotypes } 1 \text { and } 5 \text {. } \\
\text { §Serotypes } 12 \mathrm{~F}, 20 \text {, and } 33 \mathrm{~F} \text {. } \\
\text { TSerotype } 6 \mathrm{~A} \text { is not included in PPSV23. } \\
\text { \#Serotypes } 6 \mathrm{D}, 7 \mathrm{C}, 16 \mathrm{~F}, 18 \mathrm{~B}, 24 \mathrm{~F}, 34 \text {, and } 37 \text {. } \\
\text { ** Serotypes that were excluded from the statistical analysis because they were unclassifiable. }\end{array}$} \\
\hline
\end{tabular}

vaccine implementation (19), but the non-PCV7 serotypes $19 \mathrm{~A}, 15 \mathrm{~A}, 15 \mathrm{~B}, 15 \mathrm{C}$, and 24 increased each year. These results reflect simultaneous replacement of PCV7 serotypes with non-PCV7 serotypes among pneumococci that colonize the nasopharynx of children (K. Ubukata et al., unpub. data). Consequently, frequency of transmission of PCV7 serotypes from children to adults would be expected to decrease.

In this study, we found epidemiologic changes among pneumococcal strains isolated from adult patients with IPD; vaccine-type strains decreased significantly (6-9). However, the prominent decrease in serotype $6 \mathrm{~B}$ detected by our surveillance differed from findings in the United States, where serotype 14 decreased most prominently after PCV7 introduction (14). IPD cases in Japan resulting from serotype 14 decreased significantly for adults during our ongoing surveillance in 2014. Given Japan's high population density, effects of herd immunity were likely present in children and adults. However, non-PCV7 types, especially serotype $22 \mathrm{~F}$, increased.
A decrease in penicillin-nonsusceptible $S$. pneumoniae strains has been associated with serotype changes occurring after vaccine introduction $(29,30,32)$. In our previous genetic studies, the gPRSP with 3 PBP alterations encoded by the $p b p 1 a, p b p 2 x$, and $p b p 2 b$ genes also decreased significantly (19). However, our current study found increases in the gPISP with $p b p 2 x$ gene alterations that reduce susceptibilities to cephalosporin agents (e.g., cefotaxime and ceftriaxone), rather than reducing susceptibility to penicillin. This trend likely reflects preference among medical practices in Japan for cephalosporin and macrolide agents.

We also identified some gPRSPs not previously reported as new STs. Of 7 STs identified in gPRSP and non-PCV7 serotypes, 4 STs had been posted in the pneumococcal database of the MLST website: ST558 (CC558) of serotype 35B, identified in the United States (33); ST63 (CC63) of serotype 15A derived from Sweden ${ }^{15 \mathrm{~A}}-25$; ST282 (CC81) of serotype 6D in South Korea $(34,35)$; and ST83 (CC81) 
Table 5. Serotypes, resistance genotypes, and multilocus sequence type for non-PCV13 serotype isolates from adults with invasive pneumococcal diseases, Japan, April 2010-March 2013*

\begin{tabular}{|c|c|c|c|c|c|c|c|}
\hline \multirow{2}{*}{$\begin{array}{l}\text { Serotype (total } \\
\text { no. isolates) }\end{array}$} & \multirow{2}{*}{$\begin{array}{c}\text { No. isolates, } \\
\mathrm{N}=92\end{array}$} & \multirow{2}{*}{$\begin{array}{c}\text { Penicillin resistance } \\
\text { genotype }\end{array}$} & \multirow{2}{*}{$\begin{array}{c}\text { Macrolide } \\
\text { resistance gene }\end{array}$} & \multirow{2}{*}{$\begin{array}{l}\text { Clonal } \\
\text { complex }\end{array}$} & \multirow[b]{2}{*}{ ST } & \multicolumn{2}{|c|}{ Earliest report of same ST† } \\
\hline & & & & & & Year & Country (city) \\
\hline \multirow[t]{9}{*}{$6 \mathrm{C}(17)$} & 1 & $\operatorname{gPISP}(p b p 2 x+2 b)$ & $\operatorname{erm}(\mathrm{B})$ & 315 & 386 & 1996 & Portugal (Lisbon) \\
\hline & 4 & gPISP $(p b p 2 x)$ & erm(B) & 2924 & 2924 & 2003 & Japan (Hyogo) \\
\hline & 2 & gPISP $(p b p 2 x)$ & erm(B) & 2924 & 6183 & 2008 & Japan (Kanagawa) \\
\hline & 1 & $\operatorname{gPISP}(p b p 2 x)$ & erm $(B)$ & 2924 & $9336 \ddagger$ & 2012 & Japan (Fukuoka) \\
\hline & 1 & gPSSP & Non & 473 & 473 & 1994 & England (Oxford) \\
\hline & 3 & $\operatorname{gPISP}(p b p 2 x+2 b)$ & $\operatorname{erm}(\mathrm{B})$ & 156 & 5241 & 2008 & Japan (Kumamoto) \\
\hline & 2 & $\operatorname{gPISP}(p b p 2 x+2 b)$ & $\operatorname{mef}(\mathrm{A})$ & 5832 & $5025 \ddagger$ & 2012 & Japan (Kanagawa) \\
\hline & 2 & $\operatorname{gPISP}(p b p 2 x+2 b)$ & mef(A) or erm(B) & 5832 & 5832 & 2009 & Japan (Chiba) \\
\hline & 1 & $\operatorname{gPISP}(p b p 2 x+2 b)$ & $m e f(\mathrm{~A})+\operatorname{erm}(\mathrm{B})$ & 5832 & 5832 & 2009 & Japan (Chiba) \\
\hline $6 \mathrm{D}(1)$ & 1 & gPRSP & $m e f(\mathrm{~A})$ & 81 & 282 & $\begin{array}{l}1996 ; \\
2008\end{array}$ & $\begin{array}{c}\text { Vietnam [23F]; } \\
\text { South Korea [6D] }\end{array}$ \\
\hline \multirow[t]{4}{*}{$10 \mathrm{~A}(11)$} & 1 & gPISP $(p b p 2 x)$ & Non & 156 & 1263 & 1998 & $\begin{array}{l}\text { USA (Arizona/New } \\
\text { Mexico) }\end{array}$ \\
\hline & 1 & gPISP $(p b p 2 x)$ & Non & 156 & $3395 \ddagger$ & 2012 & Japan (Toyama) \\
\hline & 8 & $\operatorname{gPISP}(p b p 2 x)$ & $\operatorname{erm}(\mathrm{B})$ & 113 & 5236 & 2007 & Japan (Kanagawa) \\
\hline & 1 & $\operatorname{gPISP}(p b p 1 a+2 x)$ & erm(B) & 113 & $3078 \ddagger$ & 2012 & Japan (Yamaguchi) \\
\hline \multirow[t]{2}{*}{$11 \mathrm{~A}(5)$} & 1 & gPSSP & $\operatorname{mef}(\mathrm{A})$ & 99 & 99 & 2007 & South Korea (Seoul) \\
\hline & 4 & gPISP $(p b p 2 x)$ & $m e f(\mathrm{~A})+\operatorname{erm}(\mathrm{B})$ & 99 & 99 & 2007 & South Korea (Seoul) \\
\hline \multirow[t]{2}{*}{$15 \mathrm{~A}(8)$} & 4 & gPISP $(p b p 1 a+2 x)$ & $\operatorname{erm}(\mathrm{B})$ & 63 & 63 & 1992 & [Sweden $\left.{ }^{15 \mathrm{~A}}-25\right]$ \\
\hline & 4 & gPRSP & $\operatorname{erm}(\mathrm{B})$ & 63 & 63 & 1992 & [Sweden $\left.{ }^{15 \mathrm{~A}}-25\right]$ \\
\hline \multirow[t]{5}{*}{ 15B (6) } & 1 & gPSSP & $m e f(\mathrm{~A})$ & 199 & 199 & 1987 & [Netherlands $\left.{ }^{15 B}-37\right]$ \\
\hline & 3 & gPISP $(p b p 2 x)$ & erm(B) & 199 & 199 & 1987 & [Netherlands $\left.{ }^{15 B}-37\right]$ \\
\hline & 1 & gPISP $(p b p 2 x)$ & erm(B) & 199 & $5609 \ddagger$ & 2012 & Japan (Tokyo) \\
\hline & 1 & gPRSP & erm(B) & 81 & 83 & 1997 & Taiwan [23F] \\
\hline & & & & & & 2007 & South Korea [15] \\
\hline \multirow[t]{3}{*}{$15 \mathrm{C}(4)$} & 1 & $\mathrm{gPISP}(p b p 2 x)$ & erm(B) & 199 & 199 & 1987 & [Netherlands $\left.{ }^{15 B}-37\right]$ \\
\hline & 2 & $\operatorname{gPISP}(p b p 1 a+2 x)$ & erm(B) & 199 & 199 & 1987 & [Netherlands $\left.{ }^{15 B}-37\right]$ \\
\hline & 1 & gPRSP & erm(B) & 81 & $6138 \ddagger$ & 2013 & Japan (Tokyo) \\
\hline $16 \mathrm{~F}(1)$ & 1 & gPRSP & $\operatorname{mef}(\mathrm{A})$ & 3117 & 8351‡ & 2011 & Japan (Mie) \\
\hline $20(3)$ & 3 & gPSSP & $\operatorname{erm}(\mathrm{B})$ & 4745 & 4745 & 2005 & China (Wuhan, Hubei) \\
\hline \multirow[t]{5}{*}{$22 \mathrm{~F}(18)$} & 1 & gPSSP & Non & 433 & 433 & 1997 & Poland (center) \\
\hline & 4 & gPISP $(p b p 2 x)$ & Non & 433 & 433 & 1997 & Poland (center) \\
\hline & 10 & $\operatorname{gPISP}(p b p 2 x)$ & $m e f(\mathrm{~A})$ or erm(B) & 433 & 433 & 1997 & Poland (center) \\
\hline & 1 & $\operatorname{gPISP}(p b p 2 x)$ & $\operatorname{mef}(\mathrm{A})$ & 113 & 5236 & 2007 & Japan (Kanagawa) \\
\hline & 2 & $\operatorname{gPISP}(p b p 2 x)$ & $\operatorname{erm}(\mathrm{B})$ & 113 & 7158 & 2007 & Japan (Aichi) \\
\hline \multirow[t]{4}{*}{$23 \mathrm{~A}(9)$} & 2 & gPISP $(p b p 2 x+2 b)$ & erm(B) & 156 & 338 & 1995 & [Colombia $\left.{ }^{23 F}-26\right]$ \\
\hline & 4 & gPISP $(p b p 2 x+2 b)$ & erm(B) & 156 & 5242 & 2009 & Japan (Kumamoto) \\
\hline & 2 & $\mathrm{gPISP}(p b p 2 x+2 b)$ & erm(B) & 156 & 5246 & 2008 & Japan (Niigata) \\
\hline & 1 & gPRSP & erm(B) & 156 & $9619 \ddagger$ & 2011 & Japan (Toyama) \\
\hline \multirow[t]{4}{*}{ 35B (9) } & 2 & gPSSP & $\operatorname{erm}(\mathrm{B})$ & 1816 & 2755 & 2004 & China (Shanghai) \\
\hline & 2 & gPISP $(p b p 2 x)$ & mef(A) or erm $(\mathrm{B})$ & 1816 & 2755 & 2004 & China (Shanghai) \\
\hline & 1 & gPRSP & Non & 558 & 558 & 1999 & USA (New York) [35B] \\
\hline & 4 & gPRSP & $\operatorname{mef}(\mathrm{A})$ or $\operatorname{erm}(\mathrm{B})$ & 558 & 558 & 1999 & USA (New York) [35B] \\
\hline
\end{tabular}

of serotype15B, originating in Taiwan serotype $23 \mathrm{~F}$. The remaining $3 \mathrm{STs}$ identified in gPRSP, serotypes 15C, 16F, and 23A, appear to be novel STs arising in Japan. ST6138 of serotype 15C and ST9619 of serotype 23A were estimated to be extended from ST83 and ST338 (Pneumococcal Molecular Epidemiology Network clone Colombia ${ }^{23 F}$-26), respectively (36).

Recent pneumococcal genomic analysis $(37,38)$ indicated occurrence of capsular switching by genetic recombination among strains of different serotypes. Recombination of regions consisting of the capsular $c p s$ gene locus and 2 adjacent $p b p 1 a$ and $p b p 2 x$ genes results in capsular switching and penicillin resistance. A pneumococcal strain arising from such an event will show high penicillin resistance from mutations in $p b p$ genes because of selection pressure from antimicrobial drugs. MLST and genotypic results of gPRSPs identified in non-PCV13 strains in this study support occurrence of such genetic events.

In relation to serotypes and IPDs in adults, PPSV23 coverage has been reported to differ by disease (39). Our results show respective coverages of PCV13 and PPSV23 to be $73.9 \%$ and $84.3 \%$ for patients with pneumonia and $45.7 \%$ and $69.3 \%$ for patients with meningitis. This finding supports recommendations by the ACIP (5) for routine vaccinations with both PCV13 and PPSV23 in all adults $\geq 65$ years of age, especially those with serious underlying 
diseases. For pneumococci with a large number of capsular types, development of a novel vaccine against components other than the capsule is expected (40). Overuse of antimicrobial agents should be avoided worldwide to avoid selection of novel resistant strains capable of undermining vaccine efficacy.

This study was funded in part by a grant (Research on Emerging and Re-emerging Infectious Diseases H22-013) from the Japanese Ministry of Health, Labour and Welfare to K. U.

Dr. Ubukata is a microbiologist at Keio University School of Medicine. Her research interests include molecular epidemiology, particularly of respiratory infections, and comprehensive rapid identification of pathogens.

\section{References}

1. Alanee SR, McGee L, Jackson D, Chiou CC, Feldman C, Morris AJ, et al. Association of serotypes of Streptococcus pneumoniae with disease severity and outcome in adults: an international study. Clin Infect Dis. 2007;45:46-51. http://dx.doi.org/10.1086/518538

2. Muhammad RD, Oza-Frank R, Zell E, Link-Gelles R, Narayan KM, Schaffner W, et al. Epidemiology of invasive pneumococcal disease among high-risk adults since the introduction of pneumococcal conjugate vaccine for children. Clin Infect Dis. 2013;56:e59-67. http://dx.doi.org/10.1093/cid/cis971

3. Centers for Disease Control and Prevention. Updated recommendations for prevention of invasive pneumococcal disease among adults using the 23-valent pneumococcal polysaccharide vaccine (PPSV23). MMWR Morb Mortal Wkly Rep. 2010;59:1102-6.

4. Centers for Disease Control and Prevention. Use of 13-valent pneumococcal conjugate vaccine and 23-valent pneumococcal polysaccharide vaccine for adults with immunocompromising conditions: recommendations of the Advisory Committee on Immunization Practices (ACIP). MMWR Morb Mortal Wkly Rep. 2012;61:816-9.

5. Tomczyk S, Bennett NM, Stoecker C, Gierke R, Moore MR, Whitney CG, et al. Use of 13-valent pneumococcal conjugate vaccine and 23 -valent pneumococcal polysaccharide vaccine among adults aged $\geq 65$ years: recommendations of the Advisory Committee on Immunization Practices (ACIP). MMWR Morb Mortal Wkly Rep. 2014;63:822-5.

6. Whitney CG, Farley MM, Hadler J, Harrison LH, Bennett NM, Lynfield R, et al. Decline in invasive pneumococcal disease after the introduction of protein-polysaccharide conjugate vaccine. N Engl J Med. 2003;348:1737-46. http://dx.doi.org/10.1056/ NEJMoa022823

7. Centers for Disease Control and Prevention. Direct and indirect effects of routine vaccination of children with 7-valent pneumococcal conjugate vaccine on incidence of invasive pneumococcal disease - United States, 1998-2003. MMWR Morb Mortal Wkly Rep. 2005;54:893-7.

8. Moore MR, Gertz RE Jr, Woodbury RL, Barkocy-Gallagher GA, Schaffner W, Lexau C, et al. Population snapshot of emergent Streptococcus pneumoniae serotype 19A in the United States, 2005. J Infect Dis. 2008;197:1016-27. http://dx.doi.org/10.1086/528996

9. Pilishvili T, Lexau C, Farley MM, Hadler J, Harrison LH, Bennett NM, et al. Sustained reductions in invasive pneumococcal disease in the era of conjugate vaccine. J Infect Dis. 2010;201: 32-41. http://dx.doi.org/10.1086/648593

10. Rosen JB, Thomas AR, Lexau CA, Reingold A, Hadler JL, Harrison LH, et al. Geographic variation in invasive pneumococcal disease following pneumococcal conjugate vaccine introduction in the United States. Clin Infect Dis. 2011;53:137-43. http://dx.doi.org/10.1093/cid/cir326

11. Centers for Disease Control and Prevention. Licensure of a 13 -valent pneumococcal conjugate vaccine (PCV13) and recommendations for use among children-Advisory Committee on Immunization Practices (ACIP), 2010. MMWR Morb Mortal Wkly Rep. 2010;59:258-61.

12. Lexau CA, Lynfield R, Danila R, Pilishvili T, Facklam R, Farley MM, et al. Changing epidemiology of invasive pneumococcal disease among older adults in the era of pediatric pneumococcal conjugate vaccine. JAMA. 2005;294:2043-51. http://dx.doi.org/10.1001/jama.294.16.2043

13. Gertz RE Jr, Li Z, Pimenta FC, Jackson D, Juni BA, Lynfield R, et al. Increased penicillin nonsusceptibility of nonvaccine-serotype invasive pneumococci other than serotypes $19 \mathrm{~A}$ and $6 \mathrm{~A}$ in post-7-valent conjugate vaccine era. J Infect Dis. 2010;201:770-5. http://dx.doi.org/10.1086/650496

14. Richter SS, Heilmann KP, Dohrn CL, Riahi F, Diekema DJ, Doern GV. Pneumococcal serotypes before and after introduction of conjugate vaccines, United States, 1999-2011. Emerg Infect Dis. 2013;19:1074-83. http://dx.doi.org/10.3201/eid1907.121830

15. Miller E, Andrews NJ, Waight PA, Slack MP, George RC. Herd immunity and serotype replacement 4 years after seven-valent pneumococcal conjugate vaccination in England and Wales: an observational cohort study. Lancet Infect Dis. 2011;11:760-8. http://dx.doi.org/10.1016/S1473-3099(11)70090-1

16. Steens A, Bergsaker MA, Aaberge IS, Rønning K, Vestrheim DF. Prompt effect of replacing the 7-valent pneumococcal conjugate vaccine with the 13-valent vaccine on the epidemiology of invasive pneumococcal disease in Norway. Vaccine. 2013;31:6232-8. http://dx.doi.org/10.1016/j.vaccine.2013.10.032

17. Moore CE, Paul J, Foster D, Mahar SA, Griffiths D, Knox K, et al. Reduction of invasive pneumococcal disease 3 years after the introduction of the 13-valent conjugate vaccine in the Oxfordshire region of England. J Infect Dis. 2014;210:1001-11. http://dx.doi.org/10.1093/infdis/jiu213

18. Harboe ZB, Dalby T, Weinberger DM, Benfield T, Mølbak K, Slotved HC, et al. Impact of 13 -valent pneumococcal conjugate vaccination in invasive pneumococcal disease incidence and mortality. Clin Infect Dis. 2014;59:1066-73. http://dx.doi.org/ 10.1093/cid/ciu524

19. Chiba N, Morozumi M, Wajima T, Shouji M, Iwata S, Ubukata $\mathrm{K}$, et al. Changes in capsule and drug resistance of pneumococci after introduction of PCV7, Japan, 2010-2013. Emerg Infect Dis. 2014;20:1132-9. http://dx.doi.org/10.3201/ eid2007.131485

20. Levy MM, Fink MP, Marshall JC, Abraham E, Angus D, Cook D, et al. $2001 \mathrm{SCCM} / \mathrm{ESICM} / \mathrm{ACCP} / \mathrm{ATS} / \mathrm{SIS}$ International Sepsis Definitions Conference. Crit Care Med. 2003;31:1250-6. http://dx.doi.org/10.1097/01.CCM.0000050454.01978.3B

21. Chiba N, Morozumi M, Ubukata K. Application of the real-time PCR method for genotypic identification of beta-lactam resistance in isolates from invasive pneumococcal diseases. Microb Drug Resist. 2012;18:149-56. http://dx.doi.org/10.1089/mdr.2011.0102

22. Pan XS, Ambler J, Mehtar S, Fisher LM. Involvement of topoisomerase IV and DNA gyrase as ciprofloxacin targets in Streptococcus pneumoniae. Antimicrob Agents Chemother. 1996; 40:2321-6.

23. Clinical and Laboratory Standards Institute. Performance standards for antimicrobial susceptibility testing; $21 \mathrm{st}$ informational supplement. Vol. 31. Document M100-S21. Wayne (PA): The Institute; 2011.

24. Sakai F, Chiba N, Ono A, Yamagata Murayama S, Ubukata K, Sunakawa K, et al. Molecular epidemiologic characteristics of Streptococcus pneumoniae isolates from children with 
meningitis in Japan from 2007 through 2009. J Infect Chemother. 2011;17:334-40. http://dx.doi.org/10.1007/s10156-010-0180-3

25. Griffin MR, Zhu Y, Moore MR, Cynthia G, Whitney CG, Grijalva CG. U.S. hospitalizations for pneumonia after a decade of pneumococcal vaccination. N Engl J Med. 2013;369:155-63. http://dx.doi.org/10.1056/NEJMoa1209165

26. Angoulvant F, Levy C, Grimprel E, Varon E, Lorrot M, Biscardi S, et al. Early impact of 13-valent pneumococcal conjugate vaccine on community-acquired pneumonia in children. Clin Infect Dis. 2014;58:918-24. http://dx.doi.org/10.1093/cid/ciu006

27. Shea KM, Weycker D, Stevenson AE, Strutton DR, Pelton SI. Modeling the decline in pneumococcal acute otitis media following the introduction of pneumococcal conjugate vaccines in the US. Vaccine. 2011;29:8042-8. http://dx.doi.org/10.1016/ j.vaccine.2011.08.057

28. Taylor S, Marchisio P, Vergison A, Harriague J, Hausdorff WP, Haggard M. Impact of pneumococcal conjugate vaccination on otitis media: a systematic review. Clin Infect Dis. 2012;54:176573. http://dx.doi.org/10.1093/cid/cis292

29. Kyaw MH, Lynfield R, Schaffner W, Craig AS, Hadler J, Reingold A, et al. Effect of introduction of the pneumococcal conjugate vaccine on drug-resistant Streptococcus pneumoniae. N Engl J Med. 2006;354:1455-63. http://dx.doi.org/10.1056/ NEJMoa051642

30. Hsu HE, Shutt KA, Moore MR, Beall BW, Bennett NM, Craig AS, et al. Effect of pneumococcal conjugate vaccine on pneumococcal meningitis. N Engl J Med. 2009;360:244-56 http://dx.doi.org/10.1056/NEJMoa0800836.

31. Richter SS, Diekema DJ, Heilmann KP, Dohrn CL, Riahi F, Doern GV. Changes in pneumococcal serotypes and antimicrobial resistance after introduction of the 13-valent conjugate vaccine in the United States. Antimicrob Agents Chemother. 2014;58:6484-9. http://dx.doi.org/10.1128/AAC.03344-14

32. Hampton LM, Pan XS, Ambler J, Mehtar S, Farley MM, Schaffner W, et al. Prevention of antibiotic-nonsusceptible Streptococcus pneumoniae with conjugate vaccines. J Infect Dis. 2012;205:401-11. http://dx.doi.org/10.1093/ infdis/jir755

33. Beall B, McEllistrem MC, Gertz RE Jr, Boxrud DJ, Besser JM, Harrison LH, et al. Emergence of a novel penicillin-nonsusceptible, invasive serotype 35B clone of Streptococcus pneumoniae within the United States. J Infect Dis. 2002;186:118-22. http://dx.doi.org/ $10.1086 / 341072$

34. Song JH, Baek JY, Ko KS. Comparison of capsular genes of Streptococcus pneumoniae serotype 6A, 6B, 6C, and 6D isolates. J Clin Microbiol. 2011;49:1758-64. http://dx.doi.org/10.1128/ JCM.02628-10

35. Ko KS, Baek JY, Song JH. Multidrug-resistant Streptococcus pneumoniae serotype 6D clones in South Korea. J Clin Microbiol. 2012;50:818-22. http://dx.doi.org/ 10.1128/JCM.05895-11

36. Pai R, Gertz RE, Whitney CG, Beall B; Active Bacterial Core Surveillance Team. Clonal association between Streptococcus pneumoniae serotype 23A, circulating within the United States, and an internationally dispersed clone of serotype 23F. J Clin Microbiol. 2005;43:5440-4. http://dx.doi.org/10.1128/ JCM.43.11.5440-5444.2005

37. Brueggemann AB, Pai R, Crook DW, Beall B. Vaccine escape recombinants emerge after pneumococcal vaccination in the United States. PLoS Pathog. 2007;3:e168. http://dx.doi.org/ 10.1371/journal.ppat.0030168

38. Ko KS, Baek JY, Song JH. Multidrug-resistant Streptococcus pneumoniae serotype 6D clones in South Korea. J Clin Microbiol. 2012;50:818-22. http://dx.doi.org/10.1128/ JCM.05895-11

39. Grabenstein JD, Weber DJ. Pneumococcal serotype diversity among adults in various countries, influenced by pediatric pneumococcal vaccination uptake. Clin Infect Dis. 2014;58:85464. http://dx.doi.org/10.1093/cid/cit800

40. Lee LH, Gu XX, Nahm M. Towards new broader spectrum pneumococcal vaccines: the future of pneumococcal disease prevention. Vaccines. 2014;2:112-28 http://dx.doi.org/10.3390/ vaccines2010112.

Address for correspondence: Kimiko Ubukata, Department of Infectious Diseases, Keio University School of Medicine, 35 Shinanomachi, Shinjuku-ku, Tokyo 160-8582, Japan; e-mail: ubukatak@a6.keio.jp

\section{UPDATE MY ADDPESS Full text fire online at wWw.cdc.gov/eid}

EMERGING INFECTIOUS DISEASES ${ }^{\oplus}$

Yes, I still want the journal. Please send it to me at the address below.

Number on mailing label: (required)

Name:

The print journal is available at no charge to public health professionals

Name:

Full mailing address: (BLOCK LETTERS)

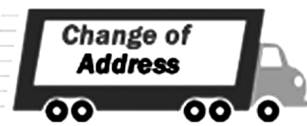

Return:

Email:eideditor@cdc.gov

Fax: 404-639-1954

or mail to:

EID Editor

CDC/OID/NCEZID

1600 Clifton Rd NE

Mailstop D61

Atlanta, GA 30329-4027 